\title{
Durable Material Deposition via PTA upon Al-alloys
}

Klara Caisova (0000-0001-6708-6214), Michal Lattner (0000-0002-3976-3940), Jaromir Cais (0000-0002-17265326)

Faculty of Mechanical Engineering, J. E. Purkyne University in Usti nad Labem. Pasteurova 3334/7, 400 01 Usti nad Labem. Czech Republic. E-mail: klara.caisova@ujep.cz

This study focuses on surface treatment of aluminium alloys by High Speed Steel (HSS30) via Plasma Transferred Arc. The main motivation of this research has been an assignment of local company in order to prolong the lifetime of a tire press molds, especially the interface of its segments. These segmented molds are made from aluminium alloy and their interface is exposed to multiple percussions, which leads to cracks. Therefore, PTA surfacing is considered as a suitable surface treatment for hardening its interface, yet benefit from lightweight of aluminium matrix. For purposes of this research AlSi9CuNiMn alloy was used as a matrix metal. Permeation in the contact zone was examined via confocal and scanning electron microscope. Hardness of affected matrix area was measured by using Vickers Hardness Tester.

Keywords: PTA, Aluminium alloys, HSS30, Inconel 625, surfacing

\section{Introduction}

Surface treamtment dealing with prolonging machineparts lifetime is nowadays a very rapidly evolving field of interest [1]. The methods used for surface treatment are around 1000 [2]. The most common metal reinforcement is the nickel-based layer deposited upon steel substrate via PTA [3, 4], laser deposition $[5,6]$ or comparison of both the above [7].

The key motivation for this research was given by the production problem of the local company and the demands from the industry for durability protective layers on the surface of the aluminum mold for the production of tires.

Aluminium based alloys are widely used materials for production due to their properties. components for the needs of the automotive and aerospace industries [8, 9]. The current trend in the automotive industry is the use of Al-Si-based suprautectic alloys to produce engine blocks and cylinders for combustion cylinders engines $[10,11]$. Among their main disadvantages in the casting process include the formation of crops, segregation of silicon particles and coarse eutectic structure [12].

\section{Material and methods}

The PTA surfacing is a physical method used for surface treatment since 1980's [13,14]. This method is based on metal powder being melting by plasma arc and its deposition upon base material surface in the form of drops (see Fig. 1).

Due to the very complicated mechanisms taking place during conducting these experiment, mathematicall models are being used in order to better understanding. These models consist of plasma stream described via Navier-Stokes equations for conservation of mass and momentum [15]. This model is based on magnetohydrodynamic aproximations with premise of laminar stream and thermodynamic equilibrium.

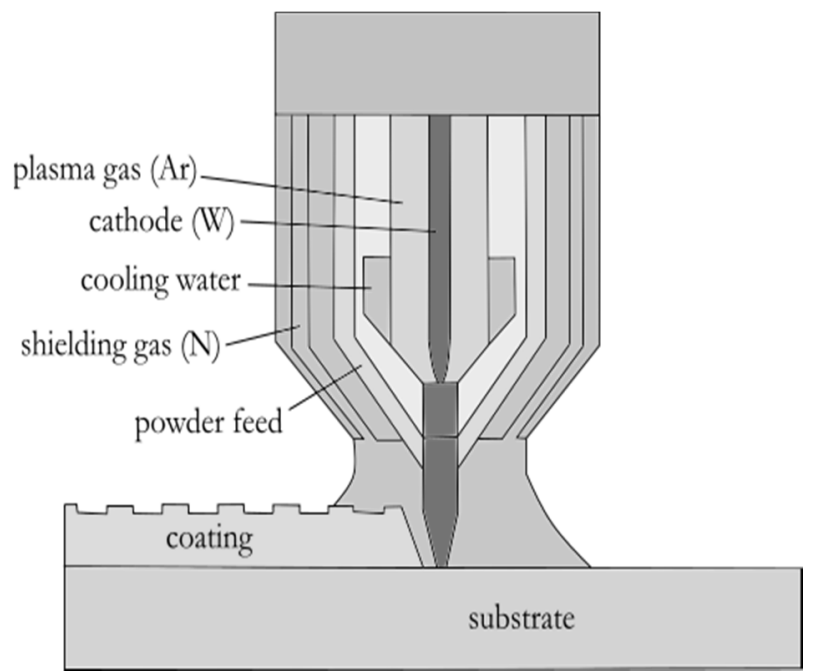

Fig. 1 Plasma Transferred Arc method principle

The PTA surfacing method is very novel approach for surface treatment with number of possible combination of materials and parameters and therefore suitable for further exploration. For purposes of this research, surfacing of aluminium based alloys via high speed steel reinforcement, has been investigated. This material combination presents new challenges of choosing suitable parameters and creating durable and merged interface of both materials. 


\section{Prepared samples}

Each sample was prepared under different parameters of PTA surfacing (see Tab. 1.). In order to explore the effect of chemical composition upon itermetallics phases, matrix composition was also differed (also Tab.1.). The different chemical composition of matrix was used in order to explore its effect on creation of different intermetallic phases and their effect on both materials interface merge.

Tab. 1 Materials and parameters used for sample preparation

\begin{tabular}{|c|c|c|c|c|c|c|}
\hline Sample & substrate & IH $[\mathrm{A}]$ & IL $[\mathrm{A}]$ & $\begin{array}{c}\text { Frequency } \\
{[\mathrm{Hz}]}\end{array}$ & $\begin{array}{c}\mathbf{v} \text { linear } \\
{\left[\mathrm{mm}_{\mathbf{s}^{-1}}\right]}\end{array}$ & Powder feed [-] \\
\hline $\mathbf{1}$ & AlSi9CuNiMn $(0.5 \% \mathrm{Mn})$ & 170 & 55 & 28.7 & 22 & 9 \\
\hline $\mathbf{2}$ & AlSi9CuNiMn $(1 \% \mathrm{Mn})$ & 170 & 55 & 28.7 & 22 & 9 \\
\hline $\mathbf{3}$ & AlSi9CuNiMn $(1.5 \% \mathrm{Mn})$ & 170 & 55 & 28.7 & 22 & 9 \\
\hline $\mathbf{4}$ & AlSi9CuNiMn $(2 \% \mathrm{Mn})$ & 170 & 55 & 28.7 & 22 & 9 \\
\hline $\mathbf{5}$ & AlSi9CuNiMn & 180 & 55 & 200 & 10 & 10 \\
\hline $\mathbf{6}$ & AlSi9CuNiMn & 212 & 55 & 200 & 16 & 10 \\
\hline $\mathbf{7}$ & AlSi9CuNiMn & 90 & 45 & 200 & 5 & 8 \\
\hline
\end{tabular}

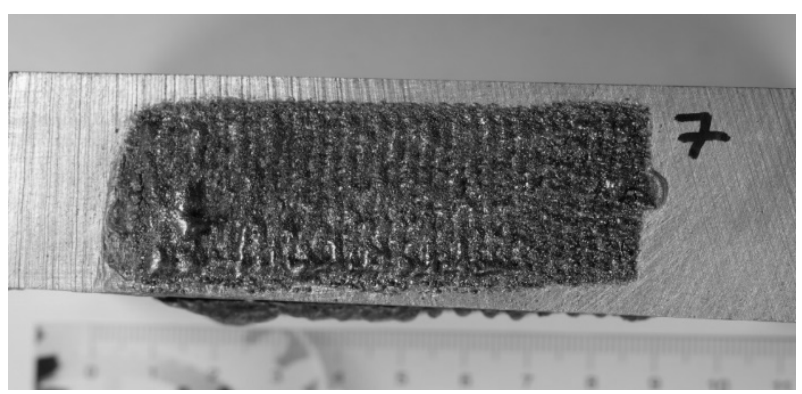

Fig. 2 Prepared sample used for further examination (Sample 7)

Prepared samples (see Fig. 2) were section cut, metallogpraphic samples were made and subjected to further analysis.

\section{Microhardness}

Tab. 2 Microhardness of prepared samples

\begin{tabular}{|c|c|c|c|}
\hline $\begin{array}{c}\text { Sam- } \\
\text { ple }\end{array}$ & $\begin{array}{c}\text { HV1 } \\
\text { (HSS30 } \\
\text { weld) }\end{array}$ & $\begin{array}{c}\text { HV0.05 } \\
\text { (recrystal- } \\
\text { ized area) }\end{array}$ & $\begin{array}{c}\text { HV0.025 } \\
\text { (base mate- } \\
\text { rial) }\end{array}$ \\
\hline $\mathbf{1}$ & 814 & 70 & 52 \\
\hline $\mathbf{2}$ & 818 & 71 & 53 \\
\hline $\mathbf{3}$ & 827 & 73 & 56 \\
\hline $\mathbf{4}$ & 831 & 79 & 58 \\
\hline $\mathbf{5}$ & 844 & 109 & 73 \\
\hline $\mathbf{6}$ & 920 & 116 & 71 \\
\hline $\mathbf{7}$ & 863 & 85 & 73 \\
\hline
\end{tabular}

All af the samples were subjected to microhardness analysis in order to examine the potential incoherence in cut section of the samples. Each sample was cut in the in the direction of welding and also perpendicularly to this direction. On each of these samples was conducted 10 measurements in three main areas (weld, recrystalized area and base material). The averages of all these measured data are presented in Tab. 2. This analysis was conducted via SHIMADZU HMV Micro Hardness Tester.

\section{Confocal microscopy}

Microstructure of all samples was examined by using Laser Confocal Microscope Olympus OLS 5000. This analysis revealed microstructure of the welded surface, merged interface of both materials and depth of recrystalized area. Due to the huge amount of energy given to the system cause the base material to melt and weld material to immerse into the recrystallization area (Fig. 3).

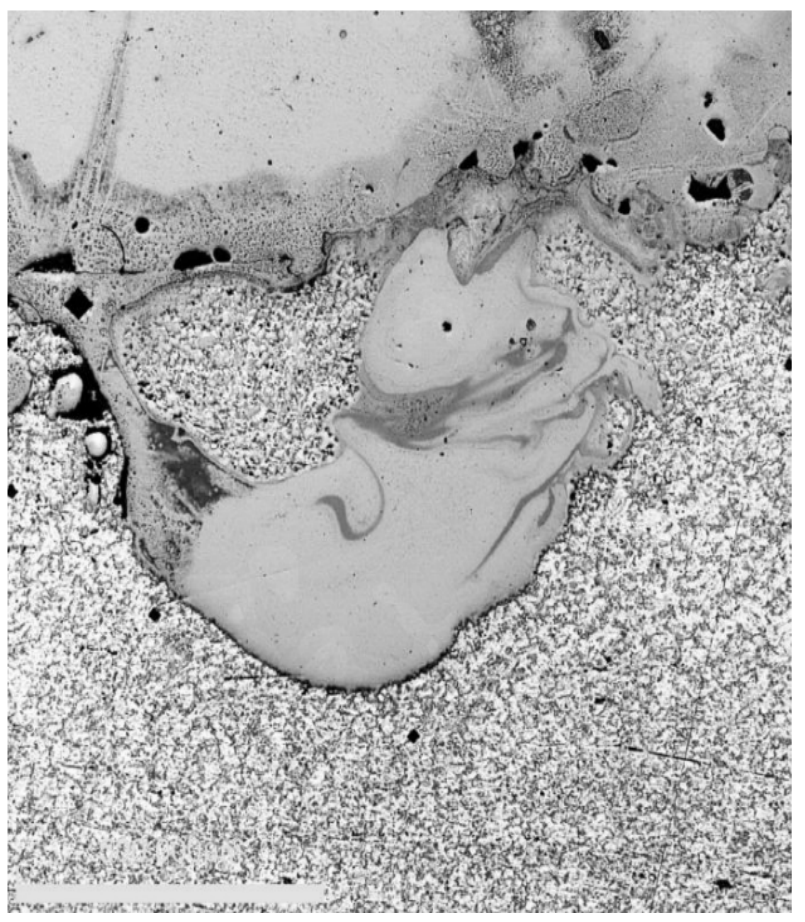

Fig. 3 Merge interface of both materials (Sample 6-cut section in the direction of welding)

Other important aspect of this analysis was to identify the level of merge of both materials. Some samples revealed a very porous interface, usually in the cut section perpendicular to the direction of welding (see Fig. 4). 


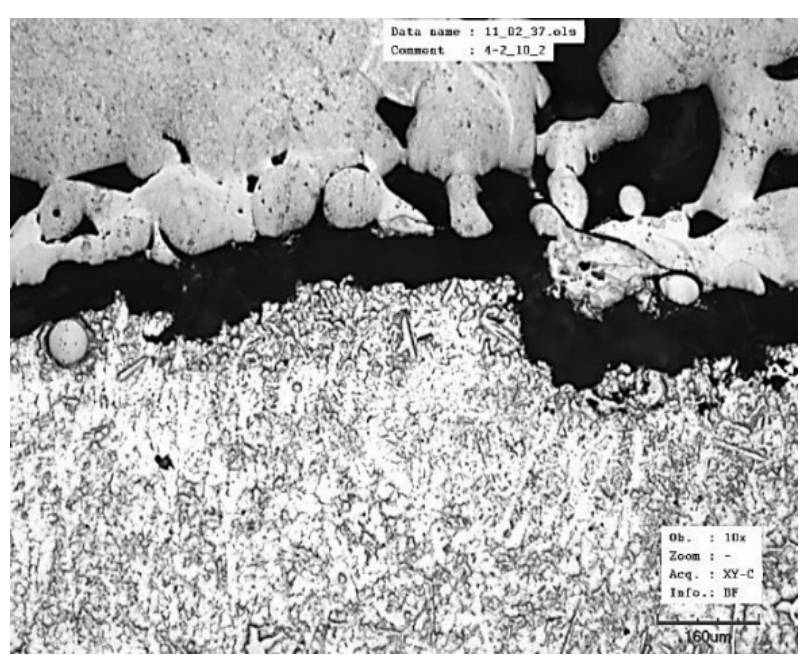

Fig. 4 Merge interface of both materials (Sample 4 - cut section in the perpendicullar direction to welding)

Also recrystalization area depth was measured. The recrystalized layer was identified by subtle grain structure compared to the rest of the base material (see Fig. 5). Each sample has benn subjected to ten measurements, the highest and the lowest values are presented in Tab. 3.

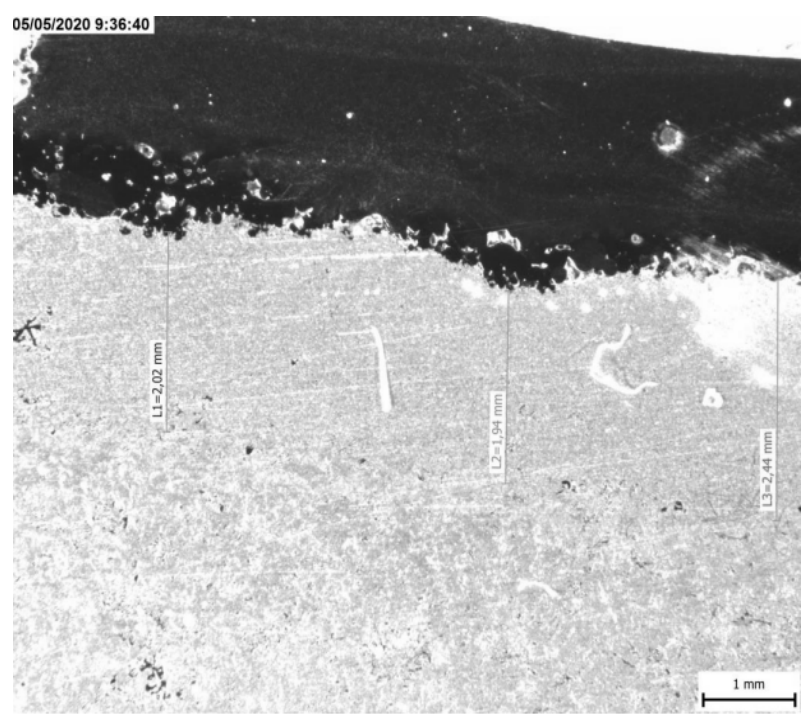

Fig. 5 Recrystalization area depth measurements (Sample 7)

Tab. 3 Recrystalized area depth measurements

\begin{tabular}{|c|c|}
\hline Sample & $\begin{array}{c}\text { Recrystalized area depth } \\
\text { measurements }[\mathrm{mm}]\end{array}$ \\
\hline $\mathbf{1}$ & $1.02-1.64$ \\
\hline $\mathbf{2}$ & $1.36-2.67$ \\
\hline $\mathbf{3}$ & $1.94-2.36$ \\
\hline $\mathbf{4}$ & $1.64-2.78$ \\
\hline $\mathbf{5}$ & $2.01-2.32$ \\
\hline $\mathbf{6}$ & $1.54-2.91$ \\
\hline $\mathbf{7}$ & $1.99-2.44$ \\
\hline
\end{tabular}

\section{Scanning electron microscopy}

Merge of both materials was examined by using Scanning Electron Microscope Tescan VEGA 3 with EDX detector Bruker X-Flash Nano. Picture presenting interface of weld and recrystalized layer is denoted as Fig. 6 (with highlited material contrast by different shape for each area by using BSE detector). Elemental mapping was also examined in the interface of both materials (see Fig. 7).

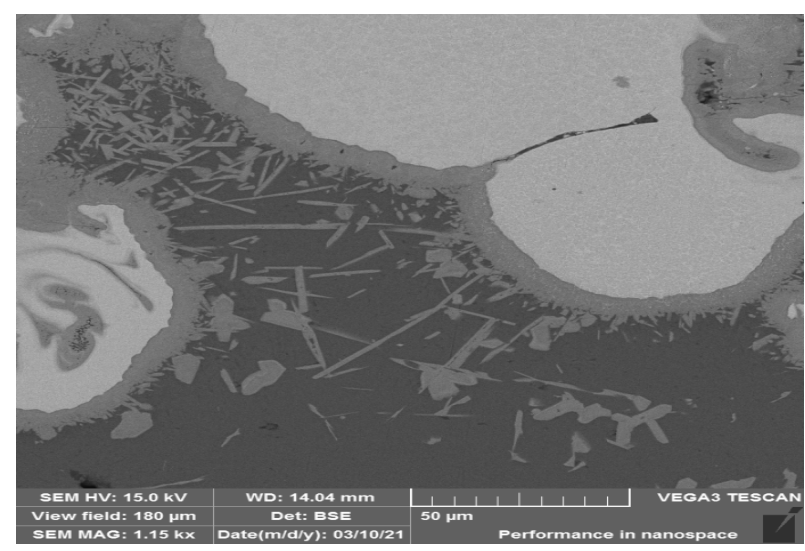

Fig. 6 Interface of weld and recrystalized base material (Sample 7)

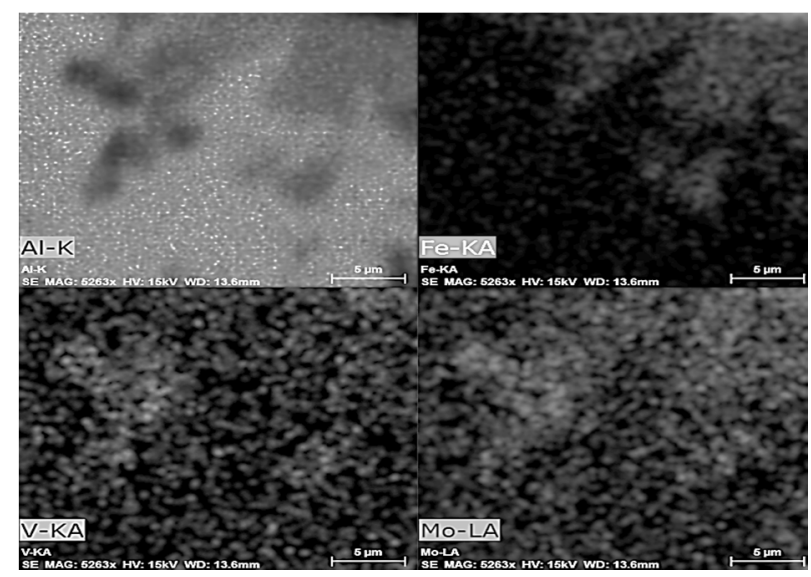

Fig. 7 Elemental mapps within interface of weld and recrystalized base material (Sample 7)

\section{Results and discussion}

Microhardness of the weld ranges between 814 and 920 HV1 in dependence of used parameters. Microhardness of recrystallized layer valued from 70 to 116 HV0.05. Microhardness of base material ranges between 52 and 73 HV0.025. Chemical composition of the alloy (different amount of $\mathrm{Mn}$ ) did not have any significant effect on the microhardness of weld of recrystallized layer. On the other hand, PTA parameters (especially frequency and plasma current) very significantly affected resultant microhardness and also cohesion of both material within merge area. Cohesion of materials is one of the key challenges within PTA surfacing upon Al-Si based alloys.

Using inconvenient parameters of PTA method 
lead to porosity within merge area between weld and base material. Also volume changes during solidification process can cause delamination of whole weld. Thickness of recrystallized layer ranged between 1.02 and $2.44 \mathrm{~mm}$ based on chemical composition of base material and parameters of PTA surfacing.

Samples showing firm cohesion of weld with base material revealed a depleted layer between weld and recrystallized layer with thickness of $10 \mu \mathrm{m}$ by using Scanning Electron Microscope. Needle-shaped intermetallic phases of $\beta$-AlFeSi has grown from this area towards the base material (recrystallized zone). Also presence of alloying elements from steel (Chrome and Vanadium) was identified within this area.

\section{Conclusion}

Following conclusions can be mentioned based on conducted experiment:

- Concentration of manganese in AlSi9CuNiMn (from 0.5 to 2 wt. \%) does not have a significant effet on interface characteristics of welded HSS30 and base material due to the extreme amount of energy input to the system.

- Coherence of weld and base materiál strongly depends on used parameters of PTA surfacing. The use of lower welding currents and speeds seems the most appropriate.

- On microstructural level, the presence of needleshaped intermetalic phase $\beta$-AlFeSi has a positive affect on merge of weld and base material.

\section{Acknowledgement}

The authors acknowledge the infrastructure and support of Science and Technology Park FSI UJEP.

\section{References}

[1] T. BURAKOWSKI, T. WIERZCHON. Surface engineering of metals: Principles, equipment, and technologies. 01199

[2] F. W. BACH, A. LAARMANN, T. WENZ. Modern Surface Technology. 082006

[3] R. GARCIA, T. LUZ, S. CANOBRE, H. COSTA. Corrosion resistance of plasma transferred arc (PTA) inconel 625 deposits. Surface Topography: Metrology and Properties, 9, 032021.

[4] H. XU, H. HUANG, Z. LIU. Influence of plasma transferred arc remelting on microstructure and properties of PTAWdeposited Ni-based overlay coating. Journal of Thermal Spray Technology, 30, 032021.

[5] M. ROMBOUTS, G. MAES, M. MERTENS, W. HENDRIX. Laser metal deposition of inconel 625: Microstructure and mechanical properties. Journal of Laser Applications, 24, 102012.
[6] J. NGUEJIO, F. SZMYTKA, S. HALLAIS, A. TANGUY, S. NARDONE, M. G. MARTINEZ. Comparison of microstructure features and mechanical properties foradditive manufactured and wrought nickel alloys 625 . Materials Science \& Engineering A, 764, 2019.

[7] P. BHARGAVA, CH. PAUL, C. PREMSINGH, S. MISHRA, A. KUMAR, D. NAGPURE, G. SINGH, L. KUKREJA. Tandem rapid manufacturing of Inconel-625 using laser assisted and plasma transferred arc depositions. Advances in Manufacturing, 1:305-313, 2013.

[8] A. J. CLEGG, A. A. DAS. Wear of a hypereutectic aluminium-silicon alloy. Wear, 43:367373, 071977.

[9] W. ABUSHANAB, E. MOUSTAFA. Effects of friction stir processing parameters on the wear resistance and mechanical properties of fabricated metal matrix nanocomposites (mmncs) surface. Journal of Materials Research and Tecbnology, 9:7460-7471, 06 2020G

[10] P. KRAUS, N. NÁPRSTKOVÁ, K. JIROUNKOVÁ, J. CAIS, J. SVOBODOVÁ, Effect of Heat Treatment on the Microstructure of the Alloy AlSi7CrMnCu2.5. Manufacturing Technology. 18. 935-942. 10.21062/ujep/204.2018/a/12132489/MT/18/6/935.

[11] N. NÁPRSTKOVÁ, R. CERVINKA, S. KUSMIERCZAK, J. CAIS, Modifications AlSi9CuMnNi Alloy by Antimony and Heat Treatment and Their Influence on the Resulting Structure. Manufacturing Technology. 15. 634638. 10.21062/ujep/x.2015/a/12132489/MT/15/4/634.

[12] M. TIRYAKIO ${ }^{-}$GLU, J. CAMPBELL, J. STALEY. The influence of structural integrity on the tensile deformation of cast $\mathrm{Al}-7 \mathrm{wt} . \% \mathrm{Si}-$ $0.6 w t . \% \mathrm{Mg}$ alloys, Scripta Materialia, 49:873878, 112003.

[13] M. BOULOS. Thermal plasma processing. Plasma Science, IEEE Transactions on, 19:1078 - 1089, 011992

[14] R. L. DEUIS, J. M. YELLUP, C. SUBRAMANIAN. Metal-Matrix Composite Coatings by PTA Surfacing. Composites Science and Technology, 58:299-309, 1998

[15] J. WILDEN, J. BERGMANN, H FRANK. Plasma transferred arc welding-modeling and experimental optimization. Journal of Thermal Spray Technology, 15:779-784, 122006. 